\title{
ENERGY CHARACTERISTICS OF PHASE REGULATING DEVICE BASED ON "STAR" CIRCUIT
}

\author{
Lev Kalinin, ORCID: 0000-0003-1894-5734, \\ Dmitrii Zaitsev, ORCID: 0000-0001-7207-1754, \\ Mihai Tirsu*, ORCID: 0000-0002-1193-6774, \\ Irina Golub, ORCID: 0000-0001-8053-9329, \\ Danila Kaloshin, ORCID: 0000-0001-7194-2175 \\ Institute of Power Engineering, 5 Academiei str., Chisinau, Republic of Moldova \\ *Corresponding author: Mihai Tirsu, tirsu.mihai@gmail.com \\ Received: 05. 12. 2021 \\ Accepted: 06. 28. 2021
}

\begin{abstract}
The electric power industry development mean increases the electric grids flexibility through the use of various devices type (FACTS) controlled by means of power electronics and being an element of the Smart Grid. This type of device includes a phaseshifting transformer (PST), which redistributes power flows in the branches of electrical networks. In connection with the relevance of this topic, new technical solutions appear that implement similar functions, which entails the need for a comparative analysis of such developments in order to optimize the energy characteristics of this kind of equipment. The aim of the work is to develop schematic version of the PST made according to the "star" scheme and analyze its operation in typical modes. During the study, the energy characteristics of the device were determined. The possibility of reducing the typical power of the phase-shifting device due to the use of capacitive compensation is analyzed.
\end{abstract}

Keywords:phase-shifting transformer, angle of phase shift, electronic power switches, control strategy, rated capacity.

\section{Introduction}

In the process of SMART GRID concept development and implementation in the electric power industry, the role of FACTS devices, which makes it possible to control the parameters of the power system mode in accordance with the chosen strategy significantly increases. The tasks of ensuring effective control of steady-state and transient modes of electric power systems can be solved by various means, one of which is phase-shifting transformer (PST).

Currently, there is a significant global experience in the use of PST [1 - 12]. Also, considerable attention is paid to the development of various technical solutions and the study of the operation modes of phase-shifting devices [13 - 19].

This work is devoted to the development and study of a two-transformer circuit version of a phase-shifting transformer made according to the "star" scheme. 


\section{General characteristics of the research object}

The work purpose is to study the energy characteristics of new technical solution of the PST made according to the "star" scheme when adjusting the phase shift angle using power electronics, as well as the use of capacitive compensation to reduce the installed power of the transformer device. During research, methods of mathematical, structural and simulation modeling were used based on the SPS-models of the object built in the Simulink (Matlab) environment.

The main elements of the investigated device are two power transformers, one of which performs the functions of parallel (or magnetizing) element, the other - the functions of series (or phase-shifting) element. The subscript " $p$ " denotes the windings and the corresponding electrical values characterizing the magnetizing transformer mode, the subscript " $q$ " denotes the windings and the electrical values of the phase-shifting transformer.

The schematic diagram of the PST technical solution considered in the work is shown in Figure 1.

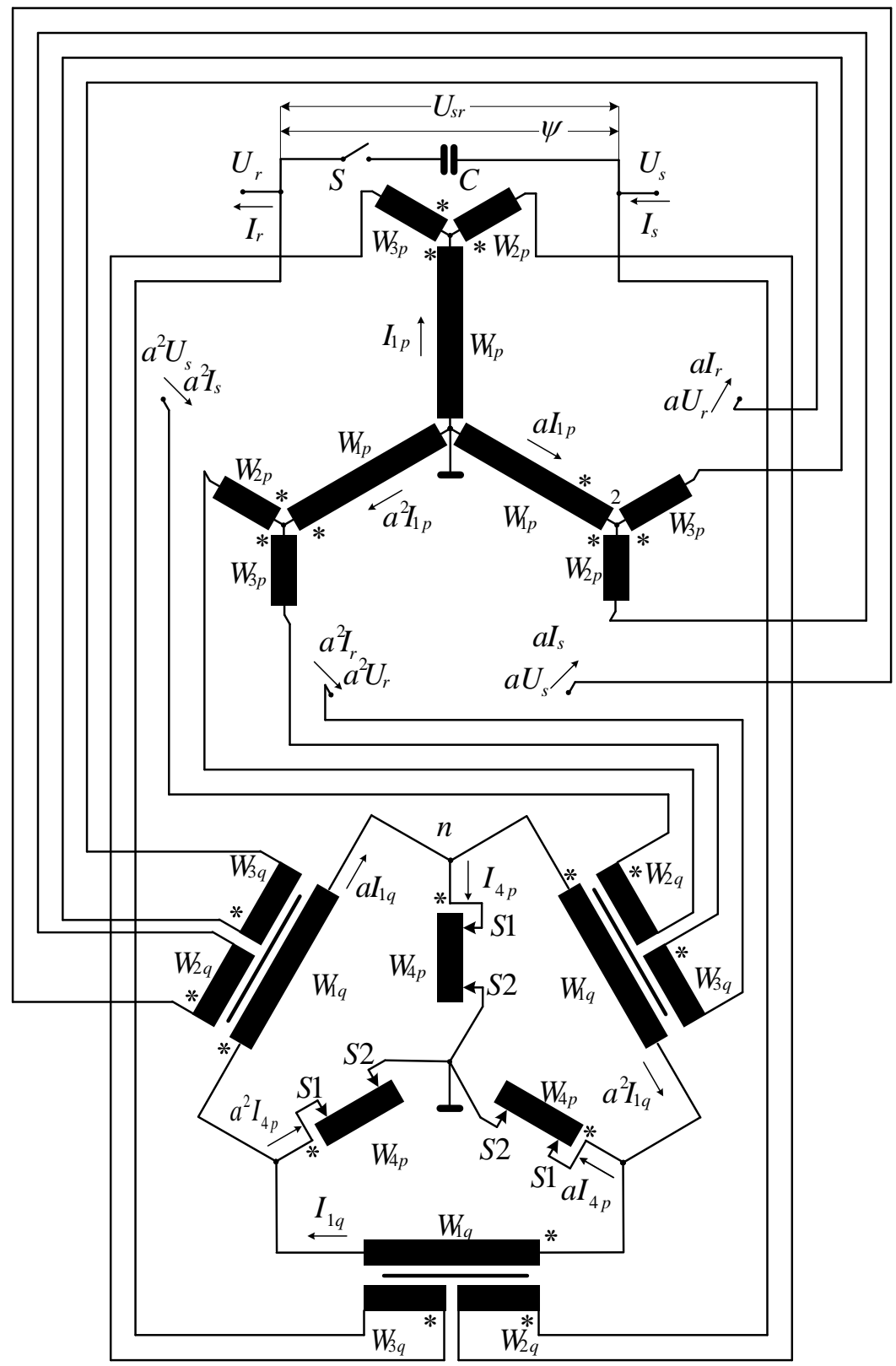

Figure 1. Technical solution of new proposed PST. 
On Figure 1 next designations are accepted:

$W_{1 p}, W_{2 p}, W_{3 p}$ - magnetizing transformer windings;

$W_{4 p}$ - regulating winding of magnetizing transformer;

$W_{1 q}, W_{2 q}, W_{3 q}$ - phase-shifting transformer windings;

$C$ - capacitor bank used to reduce the installed power of PST:

$S$ - Power key switching capacitor bank;

S1,S2 - switch mechanism contacts.

The primary windings $W_{1 p}$ of the magnetizing transformer are "star-to-zero" connected. Secondary $W_{2 p}$ and tertiary $W_{3 p}$ windings of the corresponding phases are connected to the ends of the primary windings, providing a $120^{\circ}$ shift relative to each other. The primary windings $W_{1 q}$ of the phase-shifting transformer are connected according to the "triangle" scheme, to the vertices of which the control windings $W_{4 p}$ of the magnetizing transformer assembled into a "star - to- zero" are connected. The windings $W_{2 q}, W_{3 q}$ of the phase-shifting transformer are connected in series with the corresponding windings $W_{2 p}, W_{3 p}$ of the magnetizing transformer.

Input electrical values are labeled "s-sending" and output electrical values are labeled "r-receiving", where:

$U_{s}, I_{s}$ - input voltage and current of PST;

$U_{r,} I_{r}$ - output voltage and current of PST;

$\psi$ - the phase shift angle between the input and output currents (or between the input and output voltages) provided by the voltage $U_{s r}$.

To adjust the phase shift angle between the input and output voltage of the device, it is proposed to section the control winding $W_{4 p}$ as shown in Figure 2.

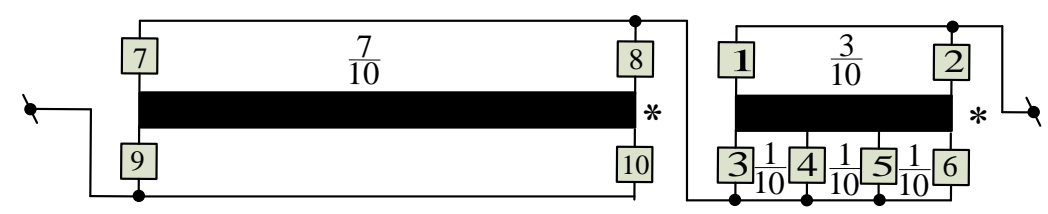

Figure 2. Control winding scheme.

Partitioning in given proportions made it possible to reduce the number of electronic keys and, when using the developed control law (Figure 3) and reversing the control winding, provide control angle $\psi$ in the range of $0^{\circ} \div 60^{\circ}$.

\begin{tabular}{|c|c|c|c|c|c|c|c|c|c|c|c|c|c|c|c|c|c|c|c|c|c|c|}
\hline \multirow{10}{*}{ 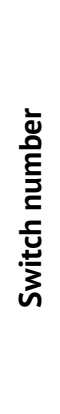 } & 10 & & & & & & & & & & & & & & & & & & & & & \\
\hline & 9 & & & & & & & & & & & & & & & & & & & & & \\
\hline & 8 & & & & & & & & & & & & & & & & & & & & & \\
\hline & 7 & & & & & & & & & & & & & & & & & & & & & \\
\hline & 6 & & & & & & & & & & & & & & & & & & & & & \\
\hline & 5 & & & & & & & & & & & & & & & & & & & & & \\
\hline & 4 & & & & & & & & & & & & & & & & & & & & & \\
\hline & 3 & & & & & & & & & & & & & & & & & & & & & \\
\hline & 2 & & & & & & & & & & & & & & & & & & & & & \\
\hline & 1 & & & & & & & & & & & & & & & & & & & & & \\
\hline \multicolumn{2}{|c|}{ Position } & +10 & +9 & +8 & +7 & +6 & +5 & +4 & +3 & +2 & +1 & 0 & 1 & - & $\begin{array}{l}- \\
3\end{array}$ & $\begin{array}{l}- \\
4\end{array}$ & - & - & $\begin{array}{l}- \\
7\end{array}$ & $\begin{array}{l}- \\
8\end{array}$ & $\begin{array}{l}- \\
9\end{array}$ & $\begin{array}{c}- \\
10\end{array}$ \\
\hline
\end{tabular}

Figure 3. Working diagram of power keys. 


\section{Device simulation}

For technical solution presented on Figure 1 in the Simulink (Matlab) software a structural-simulation model of the device was created, which was used for research and analysis of various modes of device operation.

Each PST element was modeled as a group of single-phase transformers. The parameters of the each transformer phase elements are determined for conditions $U_{s}=U_{r}=230 \mathrm{~V}$ and nominal load power of the device $10 \mathrm{kVA}$ in order to have possibility of comparative analysis and manufacture of laboratory sample. Table 1 shows the calculated currents and voltages of the magnetizing and phase-shifting transformers windings.

Table 1

\section{Currents and voltages of windings of transformer elements}

\begin{tabular}{lccccccc}
\hline & \multicolumn{4}{c}{ Magnetizing transformer windings $p$} & \multicolumn{3}{c|}{$\begin{array}{c}\text { Phase-shifting transformer } \\
\text { windings } q\end{array}$} \\
\cline { 2 - 8 } & $W_{1 p}$ & $W_{2 p}$ & $W_{3 p}$ & $W_{4 p}$ & $W_{1 q}$ & $W_{2 q}$ & $W_{3 q}$ \\
\hline$U(V)$ & 190.67 & 78.66 & 78.66 & 78.66 & 136.6 & 68.02 & 68.02 \\
\hline$I(A)$ & 10 & 12 & 12 & 12 & 12 & 11.87 & 11.87 \\
\hline
\end{tabular}

Based on the data in Table 1, the parameters of SPS - models of the phase-shifting and magnetizing elements are calculated and presented in Table 2.

Table 2

\section{Parameters of transformers SPS - models}

\section{Magnetizing transformer}

Normal power and frequency[Pn(VA) fn( $\mathrm{Hz})]$ : [1633.92 50]

Winding nominal voltages [U1 U2...Un] (Vrms):

[136.16 68.02 68.02]

Winding resistences [R1 R2...Rn] (Ohm): [0.07392 0.04004]

Winding leakage inductances [L1 L2...Ln] (H): [0.48062e-3 0.12015e-3 0.12015e-3]

Magnetization resistance $\mathrm{Rm}$ (Ohm)

1134.67

Magnetization inductance Lm (H)

1.8068

Saturation characteristic [i1(A), phi1(Vs);

i2(A), phi2;...]

$[0,0 ; 0.5931,0.6747 ; 14.8286,0.7564 ; 29.6573$,

$0.7769 ; 59.3146,0.7973 ; 177.9437 .0 .8178]$

\section{Phase-shifting transformer}

Normal power and frequency[Pn(VA) fn( $\mathrm{Hz})]$ : [1906.7 50]

Winding nominal voltages [U1 U2...Un]

(Vrms):

[190.67 78.66 78.66 78.66 78.6678.66

55.062]

Winding resistences [R1 R2...Rn] (Ohm):

[0.1195 0.04450 .04450 .00250 .00250 .0025 0.0192]

Winding leakage inductances [L1 L2...Ln] $(H)$ :

[0.8724e-3 0.14849e-3 0.14849e-3

$0.14849 \mathrm{e}-30.14849 \mathrm{e}-30.14849 \mathrm{e}-3$

$0.07276 \mathrm{e}-3]$

Magnetization resistance $\mathrm{Rm}(\mathrm{Ohm})$

1906.7

Magnetization inductance $\mathrm{Lm}(\mathrm{H})$

3.0361

Saturation characteristic [i1(A), phi1(Vs);

i2(A), phi $2 ; \ldots .$.

[0 0;0.4577 0.9448;11.4392 1.0593;22.8783

$1.0879 ; 45.7567$ 1.1165;137.27 1.1452] 
The rated power of the phase-shifting device can be decreased by a capacitor bank in parallel with the magnetizing transformer. To select the required value of the capacitor bank, the power keys are set to the position corresponding to the maximum value of the phase shift angle in the load mode. The value of the capacitor bank is selected so that the current flowing through it is equal to the current flowing through the PST. The resulting value of the capacitor bank of $C=97,39 \mathrm{mkF}$ allows you to obtain the maximum effect of reducing the installed transformer device power by transferring part of the power through the capacitor.

\section{Results of modelling}

To determine the operating characteristics of the PST, made according to the "star" scheme, in accordance with the developed program of design experiments, the device was studied in no-load and short-circuit modes. Based on the calculated experiments results, the parameters dependences of the PST equivalent circuit on the value of the phase shift angle $\psi$ and the adjustment position were obtained, shown in Figures 4, 6 and 5, 7, respectively, for options without and with the use of a capacitor bank.

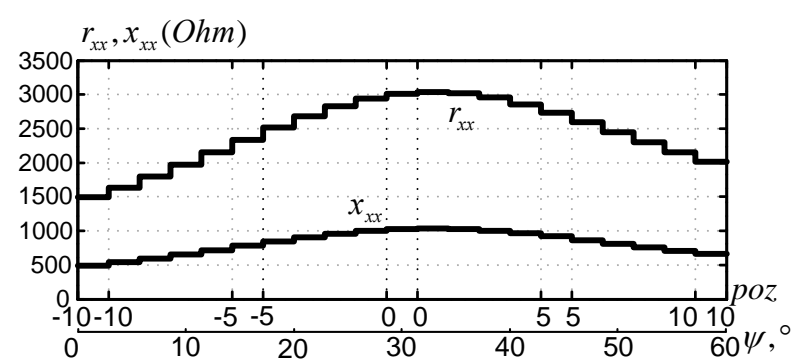

Figure 4. The characteristics of PST active $\left(r_{n l}\right)$ and reactive $\left(x_{n l}\right)$ components of resistance $\left(Z_{n l}\right)$ in no-load mode.

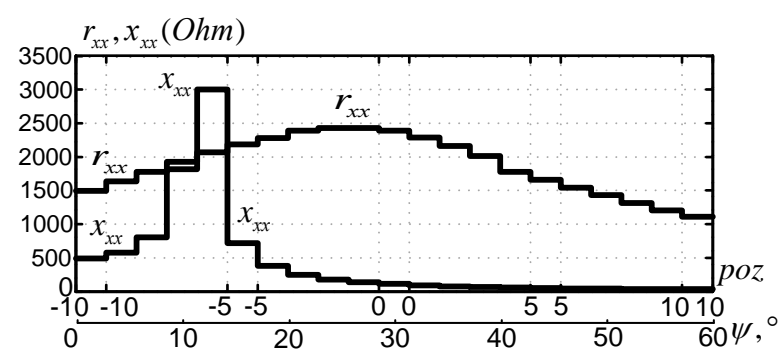

Figure 5. The characteristics of PST active $\left(r_{n l}\right)$ and reactive $\left(x_{n l}\right)$ components of resistance $\left(Z_{n l}\right)$ in no-load mode with capacitor bank.

The analysis of the dependencies presented in Figure 4 shows that the no-load resistances change smoothly and have maximum values during phase shift $\psi=30^{\circ}$ (zero position) and symmetrically decrease in the process of both decreasing and increasing the angle for the option without capacitance. The range of active resistance variation is $1500 \div$ $3000 \mathrm{Ohm}$, and the reactance is $500 \div 1000 \mathrm{Ohm}$. When using a capacitor bank (Figure 5), the nature of the change in active resistance remains the same, with the only difference that the maximum value becomes slightly less $(2500 \mathrm{Ohm})$. Inductive resistance, when using a capacitor bank, has a pronounced maximum (3000 Ohm) at a control angle of about $12^{\circ}$.

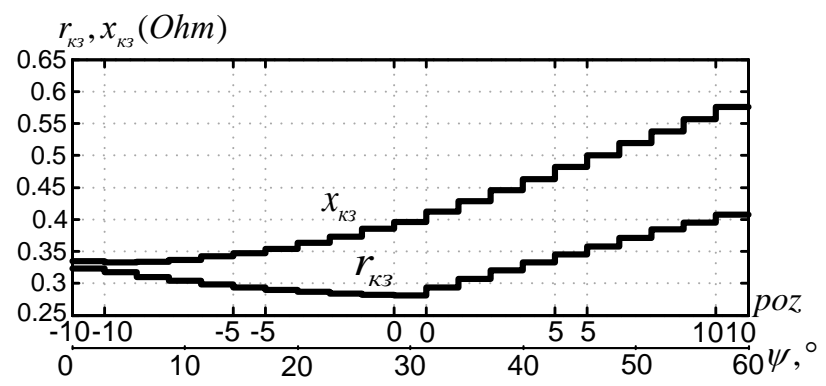

Figure 6. The characteristics of PST active $\left(r_{s c}\right)$ and reactive $\left(X_{s c}\right)$ components of resistance $\left(Z_{s c}\right)$ in short-circuit mode.

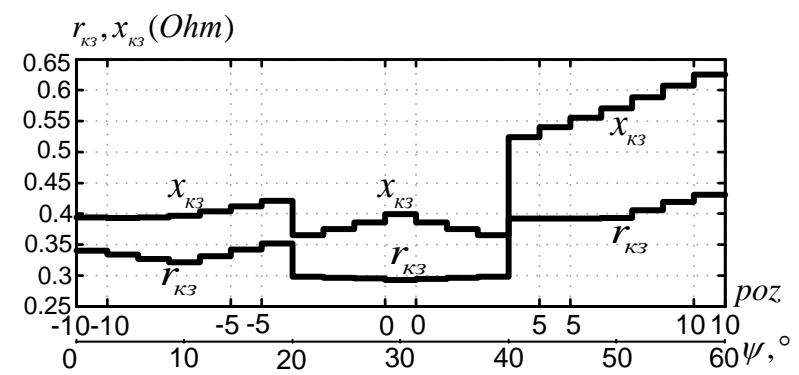

Figure 7. The characteristics of PST active $\left(r_{s c}\right)$ and reactive $\left(X_{s c}\right)$ components of resistance $\left(Z_{s c}\right)$ in short-circuit mode with capacitor bank. 
Figures 6 and 7 show the characteristics of the active $r_{s c}$ and reactive $x_{s c}$ components of the short-circuit resistance of the device $Z_{s c}$, without and with the use of a capacitor bank, respectively.

Evaluating the obtained curves (Figure 6), it can be concluded that the reactive component of the short-circuit resistance grows exponentially with increasing angle $\psi$. The minimum value of the active component falls on the angle $\psi=30^{\circ}$. The maximum values are observed at the limits of the regulation range. When using a capacitor bank (Figure 7), the dependences have a complex shape with pronounced minima in the range $20^{\circ} \div 40^{\circ}$. In addition, the graphs are located slightly higher compared to the characteristics of Figure 6.

Figures 8, 9 show the characteristics of changes in active power losses obtained as a result of open-circuit and short-circuit tests. The maximum values of active losses occur at the boundaries of the regulation range. When using a capacitor bank (Figure 9), the $\Delta P s C$ graph has a complex shape with minima in the range of $20^{\circ} \div 40^{\circ}$.

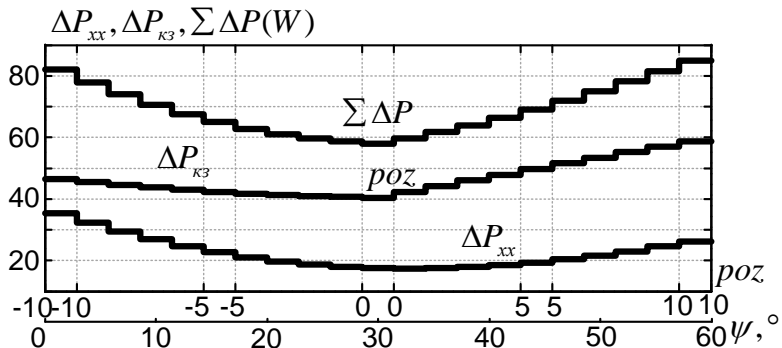

Figure 8. Dependences of PST active losses for no-load and short circuit tests.

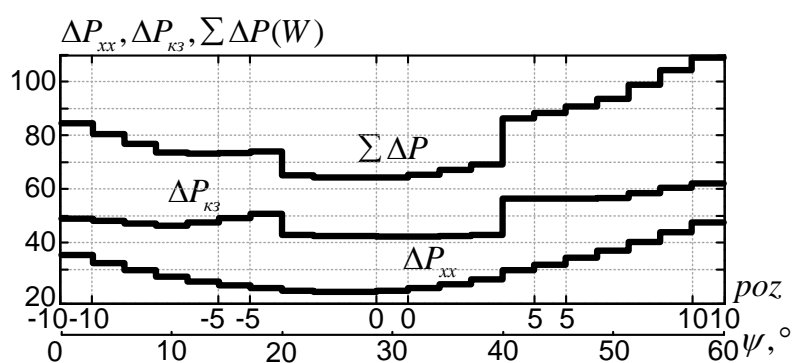

Figure 9. Dependences of PST active losses for no-load and short circuit tests with capacitor bank.

The characteristics of voltage change of the magnetizing and phase-shifting transformer windings during regulation under load are presented in Figure 10 and completely coincide with the voltage curves when using a capacitor bank.

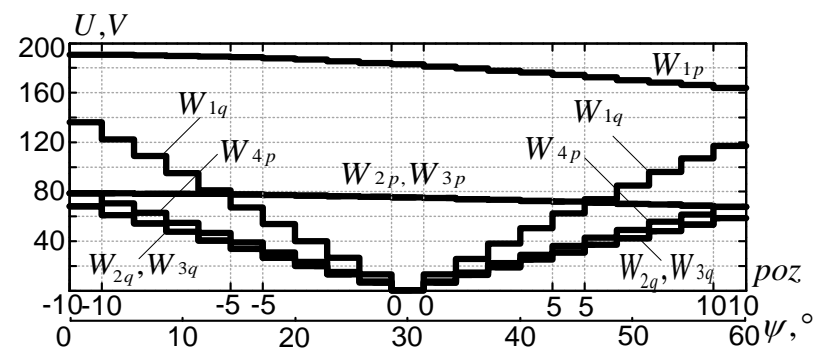

Figure 10. Voltage curves in PST windings for load mode.

As it can be seen from Figure 10, the voltages on the windings $W_{2 p}$ and $W_{3 p}$ during the angle adjustment are practically unchanged. The voltage across the winding $W_{1 p}$ decreases slightly as the angle changes $\psi=0^{\circ} \div 60^{\circ}$.

The voltage on the remaining windings of the device varied symmetrically, taking the minimum values at $\psi=30^{\circ}$ (zero regulation step), and the maximum values at $\psi=0^{\circ}$ and $\psi=60^{\circ}$, respectively.

The graphs of the device windings currents change are shown in Figures 11, 12 , respectively, for modes without and with the use of a capacitor bank. 


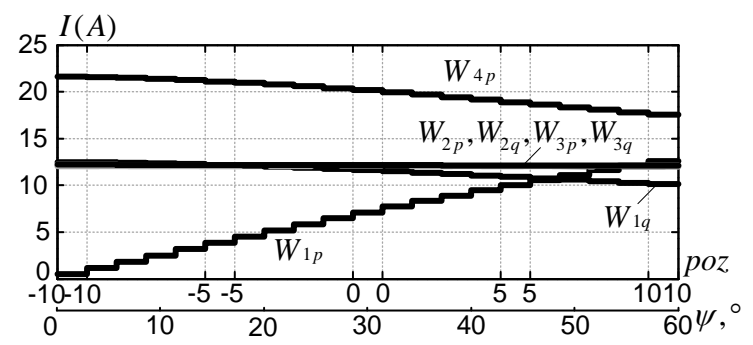

Figure 11. Currents curves of PST windings in load mode.

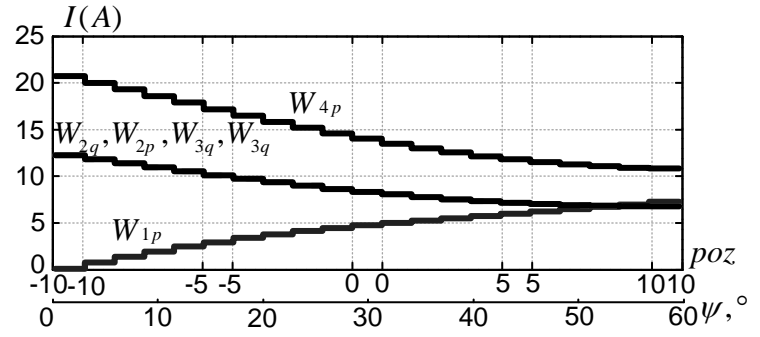

Figure 12. Currents curves of PST windings in load mode with capacitor bank.

The analysis of the presented graphs (Figure 11) shows that the currents in the windings $W_{2 p}, W_{2 q}$, and $W_{3 p}, W_{3 q}$, practically do not change during the regulation process and are equal to each other. The currents in the windings $W_{1 q}$ and $W_{4 p}$ tend to decrease exponentially with increasing angle $\psi$, while the current in the winding $W_{1 p}$ increases.

When using a capacitor bank (Figure 12), the current load of the windings is lower. The nature of the currents change in the windings $W_{2 p}, W_{2 q}$, and $W_{3 p}, W_{3 q}$ is changes (are exponential). The rest of the characteristics have similar shapes to Figure 11.

Based on the study, the energy characteristics of the research object were determined, the analysis of which made it possible to conclude about the effectiveness of the use of a capacitor bank, which made it possible to reduce the installed power of the device in relation to the throughput power from 1.64 - the original PST circuit, to 1.45 - the PST circuit with capacitor.

\section{Comparison of the research results with the previously proposed circuit variants of the device}

To determine the technical efficiency of the considered device, a comparative analysis was carried out with the previously proposed technical solution of the PST when using a capacitor bank to reduce rated power. For this, the following characteristics were used:

$S_{p s t} / S_{r}$ - coefficient characterizing the device rated power in relation to the throughput power;

$S_{r e} / S_{r}$ - coefficient characterizing the power keys capacity of the control system.

The comparative analysis results are presented in the histogram form on Figure 13 for the following PST circuit options:

- 1 - "triangle " [13,14];

- $\quad 2$ - "delta connection" [15];

- 3 - "two-transformers PST" [16];

- 4 - “double-core polygon" [17];

- 5 - "multi-polygon" [18];

- 6 - "single-transformer PST with neutral regulation" [19];

- 7 - "star" - researched device. 


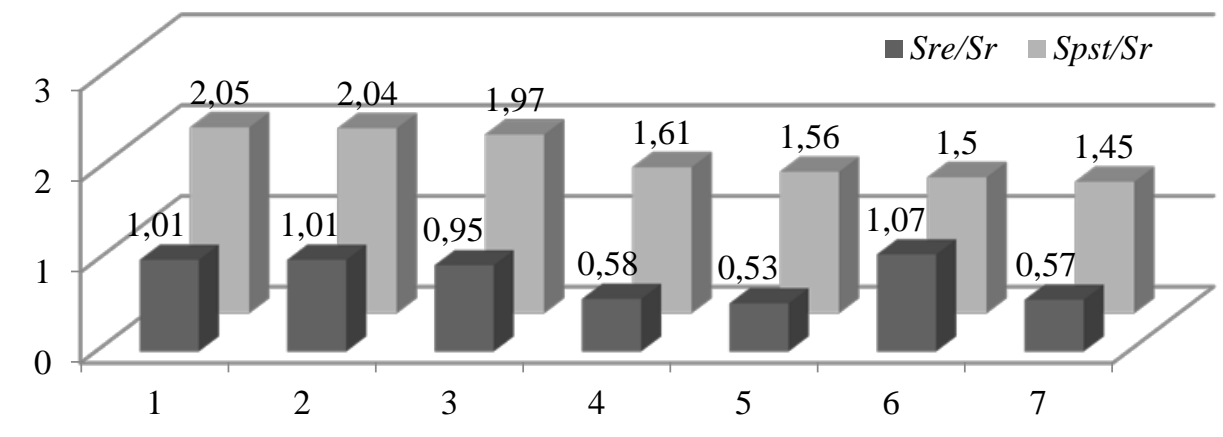

Figure 13. Histogram of the comparative analysis results of different PST solutions.

The presented histogram shows that the investigated PST solution can significantly reduce the transformer installed power, which in turn will reduce the cost of constructing devices of this type and their operating costs. Consequently, the proposed circuit variant has a competitive advantage over other PST schemes.

\section{Conclusions}

Based on the study results, the following conclusions can be drawn:

1. On the basis of the proposed PST technical solution, an analysis of the equivalent circuit parameters is carried out. The energy characteristics of the device have been determined.

2. The proposed method for reducing the installed power of investigated PST, based on the capacitor bank use connected between the input and output terminals. The optimal parameters of the capacitor bank have been determined.

3. The results analysis was carried out, which made it possible to draw a conclusion about the effectiveness of the proposed method (capacitive transmission of a part of the power), using the example of the research object.

4. The energy characteristics comparative analysis of investigated and previously developed PST technical solution showed its advantages, allowing it to be considered as an active element of modern Smart Grid systems.

5. The study results can be used for a comparative analysis of the technical solution of transformer PST developed in the future.

Acknowledgment: The results were obtained in the frame of State Program project no. 20.80009.7007.18: Eco-friendly technical solutions for efficient energy consumption in buildings and development of smart grid options with advanced renewable energy integration in Moldova.

\section{References}

1. Brochu J., Beauregard F., Cloutier R., Bergeron A., Garant L., Sirois F. Innovative applications of phase-shifting transformers supplemented with series reactive elements. Cigre 2006, A2-203

2. Dorian O. Sidea., Constantin Bulac, Valentin A. Boicea. Power engineering education toolbox for active power flow control using the phase-shifting transformer; Year: 2017; page: 177 - 183

3. Fang Z. Peng. Flexible AC Transmission Systems (FACTS) and Resilient AC Distribution Systems (RACDS) in Smart Grid; Proceedings of the IEEE; Year: 2017; page: 2099 - 2115 
4. Gopiram Maddela. Quantifying Losses in Power Systems Using Different Types of FACTS Controllers; Year: 2013.

5. Karim Shaarbafi. Transformer Modelling Guide; Year: 2017; Page: 192 - 196

6. Leonardo-Geo Mănescu, Denisa Ruşinaru, Marian Ciontu, Cosmin Buzatu, Radu Dinu, Paul Stroică. Congestion management using dispatch or phase shifting transformers; Year: 2016; Page: 1 - 6

7. Makoto Kadowaki - Hitachi LTD., Kazuhito Dobashi. Japanese Experience with the use of Phase-Shifting transformers.- Tohoku Electric Power Company ID074. Switzerland, 8 -14 september 2013

8. Mircea Eremia, Chen-Ching Liu, Abdel-Aty Edris. Phase Shifting Transformer: Mechanical and Static Devices; Advanced Solutions in Power Systems: HVDC, FACTS, and Artificial Intelligence; Year: 2016

9. Gellings C. W. The Smart Grid. Enabling Energy Efficiency and Demand Response. - CRC Press, 2010.

10. Belivanis, M.; Bell, K.R.W., Use of phase-shifting transformers on the Transmission Network in Great Britain, Universities Power Engineering Conference (UPEC), 2010 45th International. Publication Year: 2010 , Page(s): $1-5$.

11. Djordje M. Dobrijević and Jovica V. Milanović. Contribution of Phase Shifting Transformers to Improvement of the Security of Power Transfer from the Power Plant; Agia, Napa, Cyprus; 7 - 10 November 2010.

12. Hossein Nasir Aghdam. Analysis of Phase-Shifting Transformer (PST), on Congestion management and Voltage Profile in Power System by Matlab/Simulink Toolbox; Maxwell Scientific Organization, 2011.

13. Dobrusin L. Tendencii primeneniya fazopovorotnyh transformatorov, [Trends in the use of phase-shift transformers] [Power Electronics] Silovaya ehlektronika, № 4'2012 (In Russian) Available at: http://powere.ru/pdf/2012_04_60.pdf, date of access 20.12.2017

14. Golub I.V., Zaitsev D.A., Zubareva I.G. Modified Two-core Phase-shifting Transformer Based on the Classical «Delta Connection» Problemele energeticii regionale 1(30) 2016 pp. 25 - 30.

15. Kalinin L., Golub I., Zaiţev D., Tîrsu M. [Osnovnye tekhnicheskie harakteristiki dvuhtransformatornogo fazoreguliruyushchego ustrojstva.] The technical characteristics of the two-core phase-shifting device. Forumul regional al energiei pentru Europa Centrala si de Est - FOREN 201415-19 lunie 2014, Romania.

16.Tîrşu M., Calinin L., Zaiţev D., Berzan V. Phase-shift transformer with improved characteristic 9th World Energy System Conference, June 28 - 302012 Suceava, Romania http://www.agir.ro/buletine/1417.pdf.

17. Kalinin L., Zaitcev D., Tirshu M.,Golub I. The characteristics of the phase-turn transformer, made according to the scheme "polygon". Problemele Energeticii Regionale 3 (35) 2017 Electroenergetica, pp. 1 - 8.

18. Calinin L., Zaiţev D., Tîrşu M., Golub I. Regulator de fază trifazat cu transformator Institutul de Energetică al Academiei de Ştiinţe a Moldovei, MD; C/BIRegistru Patent MD, No 4397, 2016.

19. Calinin L., Zaitsev D., Tirshu M., Golub I., Moraru L. Transformator trifazat de reglare a decalajului de fază cu reglare în punctul neutru. Problemele energeticii regionale 1 (27) 2015 pp. 11 - 18 